\title{
Demethoxycurcumin induces the apoptosis of human lung cancer NCI-H460 cells through the mitochondrial-dependent pathway
}

\author{
YANG-CHING KO ${ }^{1}$, JIN-CHERNG LIEN ${ }^{2}$, HSIN-CHUNG LIU ${ }^{3}$, SHU-CHUN HSU ${ }^{3}$, BIN-CHUAN JI ${ }^{4}$, \\ MEI-DUE YANG ${ }^{5}$, WU-HUEI HSU ${ }^{1,6}$ and JING-GUNG CHUNG ${ }^{3,7}$ \\ ${ }^{1}$ Graduate Institute of Clinical Medical Science, ${ }^{2}$ Graduate Institute of Pharmaceutical Chemistry, and \\ ${ }^{3}$ Department of Biological Science and Technology, China Medical University, Taichung 404; \\ ${ }^{4}$ Division of Chest Medicine, Department of Internal Medicine, Changhua Christian Hospital, Changhua 500; \\ Departments of ${ }^{5}$ Surgery, ${ }^{6}$ Internal Medicine, China Medical University Hospital, Taichung 404; \\ ${ }^{7}$ Department of Biotechnology, Asia University, Taichung 404, Taiwan, R.O.C.
}

Received December 15, 2014; Accepted February 10, 2015

DOI: 10.3892/or.2015.3865

\begin{abstract}
Lung cancer is the most common cause of cancerrelated mortality in the US as well as other regions of the world. Curcumin, demethoxycurcumin (DMC) and bisdemethoxycurcumin (BDMC) are the major components of Curcuma longa $\mathrm{L}$. It has been reported that curcumin inhibits the growth of various types of cancer cells in vitro and in vivo. However, the mechanisms involved in the inhibition of cell growth and induced apoptosis by DMC in human lung cancer cells remain unclear. In the present study, we investigated the effect of DMC on cell death via the induction of apoptosis in NCI-H460 human lung cancer cells. Flow cytometric assay was used to examine the total percentage of viable cells, the population of cells in the sub-G1 phase of the cell cycle, the level of reactive oxygen species (ROS), $\mathrm{Ca}^{2+}$ production, mitochondrial membrane potential $(\Delta \Psi \mathrm{m})$ and caspase activity. Western blotting was used to examine the changes in the expression of cell cycle- and apoptosis-associated proteins. Confocal microscopy was used to examine the translocation of apoptosis-associated proteins. The results indicated that DMC significantly induced cell morphological changes and decreased the percentage of viable NCI-H460 cells and DMC induced apoptosis based on the cell distribution in the sub-G1 phase. Moreover, DMC promoted ROS and $\mathrm{Ca}^{2+}$ production and decreased the level of $\Delta \Psi \mathrm{m}$ and promoted the activities of caspase-3, -8 and -9 . The Western blotting results showed
\end{abstract}

Correspondence to: Professor Jing-Gung Chung, Department of Biological Science and Technology, China Medical University, 91 Hsueh-Shih Road, Taichung 404, Taiwan, R.O.C.

E-mail: jgchung@mail.cmu.edu.tw

Dr Wu-Huei Hsu, Department of Internal Medicine, China Medical University Hospital, Taichung 404, Taiwan, R.O.C.

E-mail: hsuwh@mail.cmuh.org.tw

Key words: demethoxycurcumin, NCI-H460 cells, mitochondria, sub-G1 phase, apoptosis that DMC promoted the expression of AIF, Endo G and PARP. The levels of Fas ligand (Fas L) and Fas were also upregulated. Furthermore, DMC promoted expression of ER stress-associated proteins such as GRP78, GADD153, IRE1 $\beta$, ATF-6 $\alpha$, ATF- $6 \beta$ and caspase- 4 . Based on the findings, we suggest that DMC may be used as a novel anticancer agent for the treatment of lung cancer in the future.

\section{Introduction}

Non-small cell lung carcinoma is one of the leading causes of cancer-related mortality worldwide (1). Standard platinum-based chemotherapies provide marginal improvement in survival at the expense of substantial toxicity (2). Even with the addition of targeted therapy, the median survival of metastatic non-small cell lung cancer patients is approximately one year (3). Due to the unsatisfactory results of standard chemotherapy, the identification of new drugs is crucial.

In recent years, the public has become increasingly aware of alternative medical therapies through all forms of media in Western countries, and the use of complementary and alternative medicine has also increased, particularly among oncology patients. Curcumin, isolated from turmeric (Curcuma longa L.), contains curcumin as a major component but also contains demethoxycurcumin (DMC) and bisdemethoxycurcumin (BDMC), respectively (4). Extensive research during the last half century has revealed several important functions of curcumin such as antioxidant, anti-inflammatory and anticancer properties (5-7). Recently, more and more studies have demonstrated the stronger activity of DMC when compared with curcumin in many aspects (8-10). Numerous studies have shown that DMC induces cytotoxic effects in many cancer cell lines such as colon (11) and renal cell cancer (12), glioma (9) and leukemic cell lines (13). However, no study exists which shows the effects of DMC on human lung cancer cells, and the role of DMC in inducing cell cycle arrest and apoptosis has never been investigated in detail.

The NCI-H460 cell line is derived from human large cell lung cancer, which is one of the major types of non-small cell lung carcinoma. In the present study, we investigated the 
cytotoxic effects of DMC on human lung cancer NCI-H460 cells and we found that DMC induced cell death through the induction of apoptosis in vitro.

\section{Materials and methods}

Chemicals and reagents. DMC, dimethyl sulfoxide (DMSO), propidium iodide (PI) and Trypsin-EDTA were purchased from Sigma Chemical Co. (St. Louis, MO, USA). Culture medium RPMI-1640, fetal bovine serum (FBS), L-glutamine and penicillin-streptomycin were purchased from Gibco/Invitrogen Life Technologies (Carlsbad, CA, USA). Primary antibodies (anti-AIF, -Endo G, -GRP78, -GADD153, -IRE1 $\beta$, -ATF-6 $\alpha$, -ATF-6 $\beta$, and -caspase-4) were obtained from Santa Cruz Biotechnology, Inc. (Santa Cruz, CA, USA).

Cell culture. The human lung cancer cell line NCI-H460 was purchased from the Food Industry Research and Development Institute (Hsinchu, Taiwan). The cells were cultured in RPMI-1640 medium supplemented with $10 \%$ FBS, $100 \mathrm{U} / \mathrm{ml}$ penicillin, $100 \mu \mathrm{g} / \mathrm{ml}$ streptomycin and $2 \mathrm{mM}$ glutamine and were incubated in a $5 \% \mathrm{CO}_{2}$ humidified incubator at $37^{\circ} \mathrm{C}$ in a $75-\mathrm{cm}^{2}$ tissue culture flask.

Assessment of cell morphological changes and viability. NCI-H460 cells were plated onto 12-well plates at a density of $2 \times 10^{5}$ cells/well, and DMC was added at final concentrations of $0,15,20,25,30$ or $35 \mu \mathrm{M}$. In control wells, only DMSO (solvent) was added. The cells were exposed for 24 and $48 \mathrm{~h}$. A phase-contrast microscope was used to observe morphological changes in the examined cells at the end of the time period. Cell viability was estimated through flow cytometric methods as described elsewhere $(14,15)$.

Cell cycle distribution and sub-G1 assays. Approximately $2 \times 10^{5}$ cells/well of NCI-H460 cells in 12-well plates were incubated with $0,15,20,25,30,35$ and $40 \mu \mathrm{M}$ of DMC for $48 \mathrm{~h}$. The cells were harvested by centrifugation, washed with PBS and fixed in $70 \%$ ethanol at $-20^{\circ} \mathrm{C}$ overnight. The cells were then resuspended in PBS containing $40 \mu \mathrm{g} / \mathrm{ml}$ of PI, $0.1 \mathrm{mg} / \mathrm{ml}$ RNase and $0.1 \%$ Triton X-100 in a dark room for $30 \mathrm{~min}$ and were subsequently analyzed by a flow cytometer (FACSCalibur; Becton-Dickinson, San Jose, CA, USA) (16,17). The cell cycle distribution and sub-G1 groups (apoptosis) were calculated and analyzed by CellQuest (Becton-Dickinson) and ModFit LT software (Verity Software House Inc., Topsham, ME, USA).

Reactive oxygen species (ROS), intracellular $\mathrm{Ca}^{2+}$ and mitochondrial membrane potential $(\Delta \Psi m)$ assays. NCI-H460 cells $\left(2 \times 10^{5}\right.$ cells/well) were treated with $35 \mu \mathrm{M}$ of DMC for different time intervals. At the end of the incubation, cells from each treatment and time-points were collected, washed, counted and then were resuspended in $500 \mu \mathrm{l}$ of DCFH-DA $(10 \mu \mathrm{M})$ for $30 \mathrm{~min}$ for ROS $\left(\mathrm{H}_{2} \mathrm{O}_{2}\right)$ measurement, resuspended in $500 \mu \mathrm{l}$ of Fluo-3/AM $(2.5 \mu \mathrm{g} / \mathrm{ml})$ for $30 \mathrm{~min}$ for intracellular $\mathrm{Ca}^{2+}$ concentration measurement and resuspended in $500 \mu \mathrm{l}$ of $\mathrm{DiOC}_{6}(4 \mu \mathrm{mol} / \mathrm{l})$ for $30 \mathrm{~min}$ to determine the levels of $\Delta \Psi \mathrm{m}$. All samples were then individually analyzed by flow cytometry as described previously (16).
Caspase-3, -8 and -9 activity assay. NCI-H460 cells were plated onto 12-well plates at a density of $2 \times 10^{5}$ cells/well and incubated with or without $35 \mu \mathrm{M}$ DMC. The cells were then incubated for $0,6,24$ and $48 \mathrm{~h}$ and harvested, washed and resuspended in $25 \mu \mathrm{l}$ of $10 \mu \mathrm{M}$ substrate solution (PhiPhiLux and CaspaLux kit; OncoImmunin, Inc., Gaithersburg, MD, USA) before being incubated at $37^{\circ} \mathrm{C}$ for $60 \mathrm{~min}$. The cells were washed again in PBS and were analyzed by flow cytometry as described previously $(16,18,19)$.

Effects of DMC on expression of apoptosis-associated proteins as determined by western blot analysis. Cells $\left(2 \times 10^{6} \%\right.$ dish) were treated with $35 \mu \mathrm{M}$ DMC and incubated for $0,6,24$ and $48 \mathrm{~h}$. The abundance of selective proteins associated with apoptosis was determined by western blotting. Briefly, at the end of the incubation, the cells were harvested and lysed as described previously $(18,19)$. The levels of apoptosisassociated proteins were determined in the cell lysates using primary antibodies (those associated with the cell cycle such as anti-p21, p27, CDC25c, CDK2, cyclin A and cyclin E; those associated with apoptosis such as anti-AIF, Endo G, PARP, Fas-L and Fas; those associated with ER stress such as ATF6 $\alpha$, ATF-6 $\beta$, IRE1 $\beta$, GRP78, GADD153, caspase-4 and -12). For equal protein loading, each membrane was stripped and reprobed with the anti- $\beta$-actin antibody $(18,19)$.

Confocal laser scanning microscopy. NCI-H460 cells $\left(3 \times 10^{5}\right.$ cells/well) were placed on 6 -well chamber slides and incubated with or without $35 \mu \mathrm{M}$ DMC for $48 \mathrm{~h}$. The cells were then fixed, washed and permeabilized as described previously $(16,17)$. Then anti-AIF, Endo G, ATF6 $\beta$, IRE1 $\alpha$ and p-PERK (all in green fluorescence) were individually used for staining each sample overnight, followed by washing and then staining with the secondary antibody (FITC-conjugated goat anti-mouse IgG). The cells were then stained using PI (red fluorescence) for nuclear examination under a Leica TCS SP2 confocal spectral microscope as described previously $(16,17)$.

Statistical analysis. All data are expressed as the mean \pm SD of 3 experiments. Statistical analysis was performed using the Student's t-test, with a value of $\mathrm{P}<0.05$ considered to indicate a statistically significant difference between the DMC-treated and untreated (control) group.

\section{Results}

DMC induces cell morphological changes and decreases the cell viability of NCI-H460 cells. The NCI-H460 cells were treated with various concentrations of DMC for 24 and $48 \mathrm{~h}$ and then were photographed to examine morphological changes. The percentage of total viable cells was then determined. DMC significantly induced cell morphological changes in a concentration-dependent manner and these changes were based on an increase in cell death and debris (Fig. 1A and B). The flow cytometric assay indicated that DMC decreased the percentage of viable cells in a concentration-dependent manner (Fig. 1C).

Cell cycle arrest and apoptosis of the NCI-H460 cells after treatment with DMC. The cell cycle distribution of the 

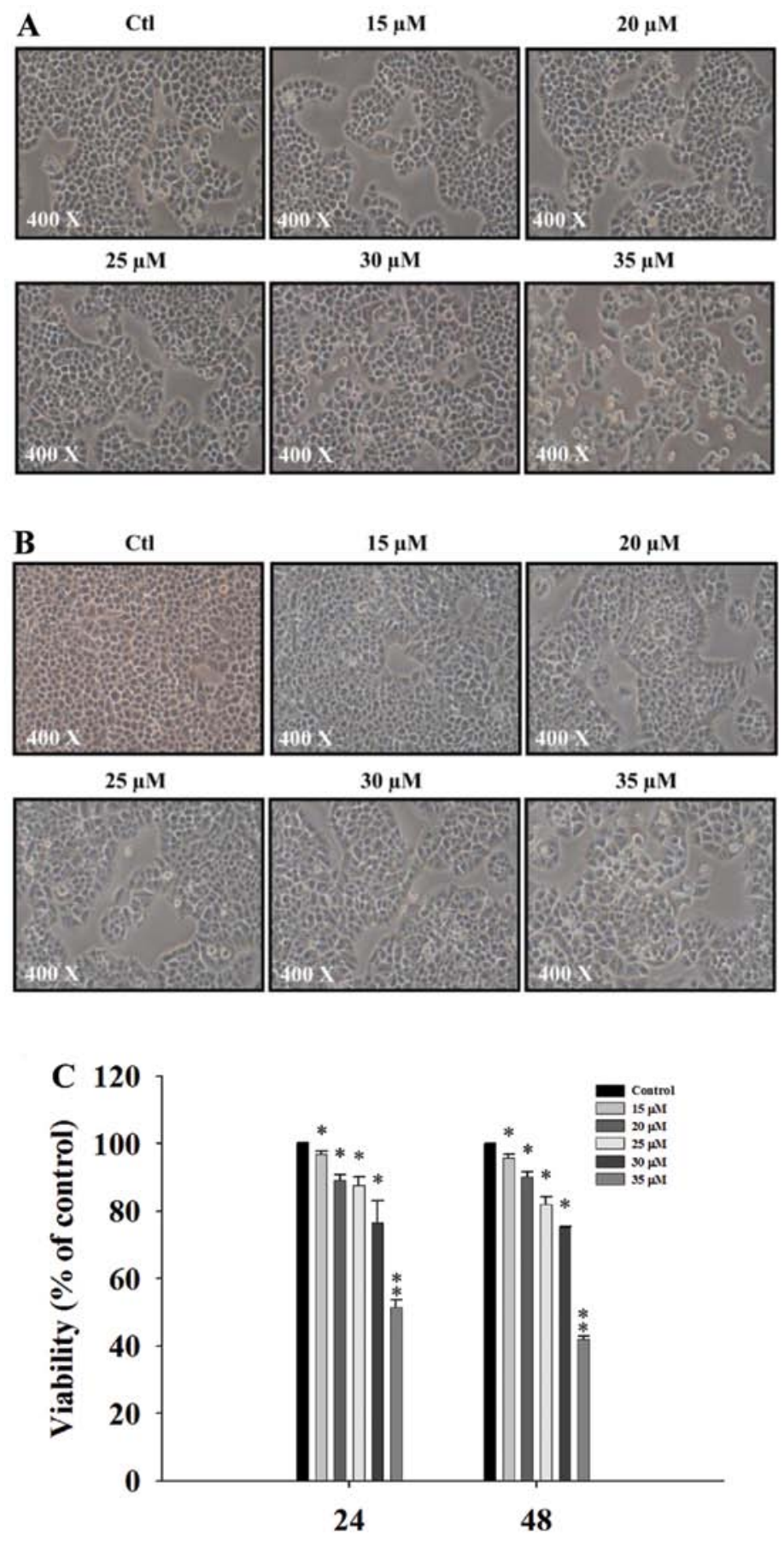

Time of incubation (h)

Figure 1. DMC induces cell morphological changes and decreases the percentage of viable NCI-H460 cells. The NCI-H460 cells were treated with $0,15,20,25$, 30 and $35 \mu \mathrm{M}$ of DMC for 24 and $48 \mathrm{~h}$, and the cells were photographed to examine cell morphological changes (A and B) and were harvested for measuring the percentage of viable cells $(\mathrm{C})$ which was determined by flow cytometry as described in Materials and methods. ${ }^{\mathrm{P}}<0.05$, significant difference between the DMC-treated group and the control as analyzed by Student's t-test. DMC, demethoxycurcumin.

NCI-H460 cells after treatment with $0,15,20,25,30,35$ and $40 \mu \mathrm{M}$ of DMC for $48 \mathrm{~h}$ is shown in Fig. 2A. Cell cycle arrest appeared to occur at the $\mathrm{S}$ stage after exposure to DMC. The sub-G1 peak, indicating the proportion of apoptosis, increased in a dose-dependent manner when the concentration of DMC was increased (Fig. 2B).

Effects of DMC on ROS production, $\triangle \Psi m$ and intracellular $\mathrm{Ca}^{2+}$ levels in the NCI-H460 cells. Following DMC treatment for different time intervals, ROS (Fig. 3A) and intracellular $\mathrm{Ca}^{2+}$ (Fig. 3C) were significantly increased as compared with the control group. In addition, there was a significant loss of $\Delta \Psi \mathrm{m}$ after treatment with $35 \mu \mathrm{M}$ of DMC (Fig. 3B).

DMC promotes the activity of caspase- $3,-8$ and -9 in the NCI-H460 cells. After treatment with DMC for different durations, the NCI-H460 cells exhibited increased caspase-3 activity. The caspase- 3 activity reached its maximum when 

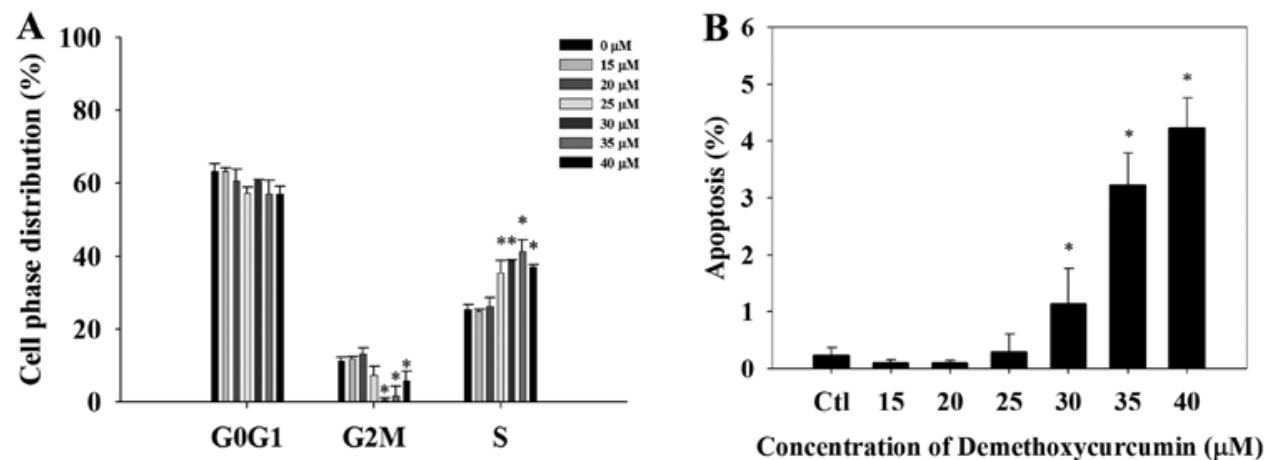

Figure 2. DMC promotes $\mathrm{S}$ phase arrest and causes apoptosis of the NCI-H460 cells. The cells were treated with different concentrations of DMC for $48 \mathrm{~h}$. The distribution of the cell cycle and sub-G1 (apoptosis) peaks were measured by flow cytometric assay. (A) The percentage of cell cycle distribution. (B) Apoptosis (\%). Significant difference from the control at ${ }^{*} \mathrm{P}<0.05$ by Student's t-test. DMC, demethoxycurcumin.
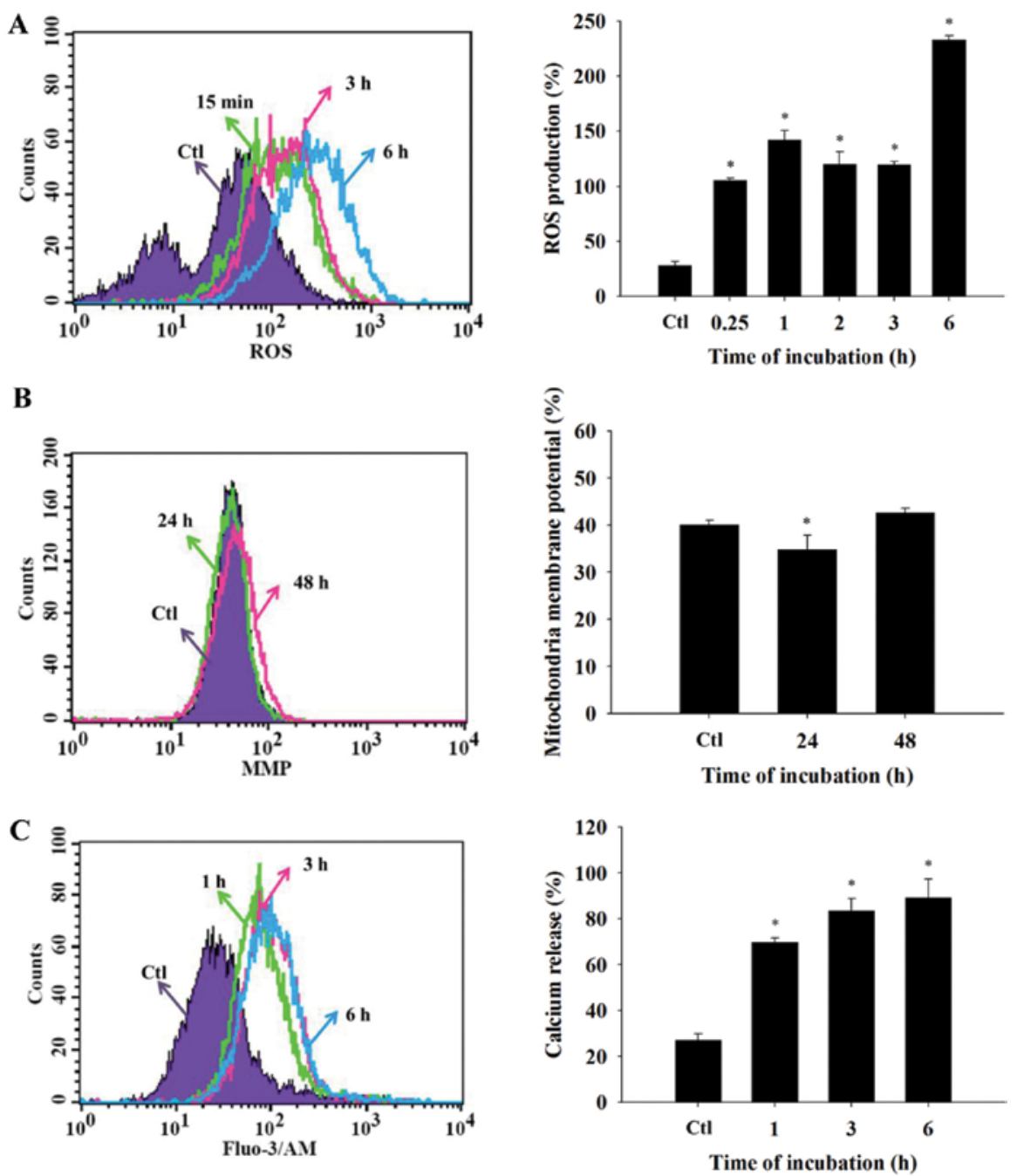

Figure 3. DMC induces reactive oxygen species (ROS) and $\mathrm{Ca}^{2+}$ production and decreases the mitochondrial membrane potential $(\Delta \Psi \mathrm{m})$ in NCI-H460 cells. NCI-H460 cells $\left(2 \times 10^{5}\right.$ cells/well) were treated with $35 \mu \mathrm{M}$ of DMC for different time periods. All cells were harvested and were immediately resuspended in $500 \mu \mathrm{l}$ of DCFH-DA $(10 \mu \mathrm{M})$ for 30 min for ROS $\left(\mathrm{H}_{2} \mathrm{O}_{2}\right)$ measurement (A), resuspended in $500 \mu \mathrm{l}$ of $\mathrm{DiOC}_{6}(4 \mu \mathrm{mol} / \mathrm{l})$ for 30 min to measure the levels of $\Delta \Psi \mathrm{m}(\mathrm{B})$, and resuspended in $500 \mu \mathrm{l}$ of Fluo-3/AM $(2.5 \mu \mathrm{g} / \mathrm{ml})$ for $30 \mathrm{~min}$ to assess the intracellular $\mathrm{Ca}^{2+}$ concentration (C) as described in Materials and methods. The results are shown as a mean $\pm \mathrm{SD}(\mathrm{n}=3) ;{ }^{*} \mathrm{P}<0.05$, significant difference between the DMC-treated group and the control as analyzed by Student's t-test. DMC, demethoxycurcumin.

the duration of treatment was $48 \mathrm{~h}$. The caspase- 8 and -9 activities in the NCI-H460 cells were also increased following treatment of DMC at $35 \mu \mathrm{M}$ (Fig. 4). These effects were time-dependent with the exception of the 24-h incubation, which showed a reduction in activity compared with the 6-h treatment. 
A

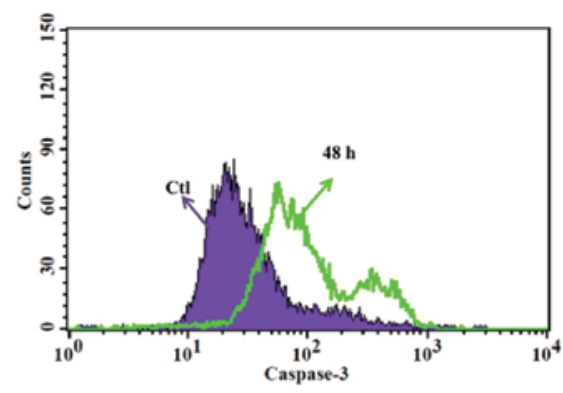

B

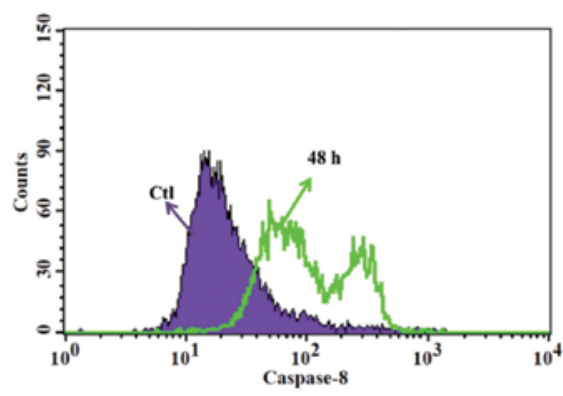

C

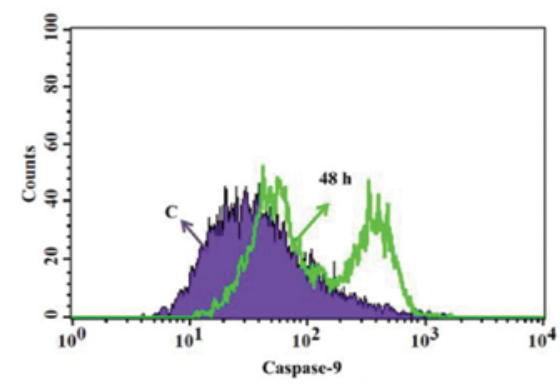

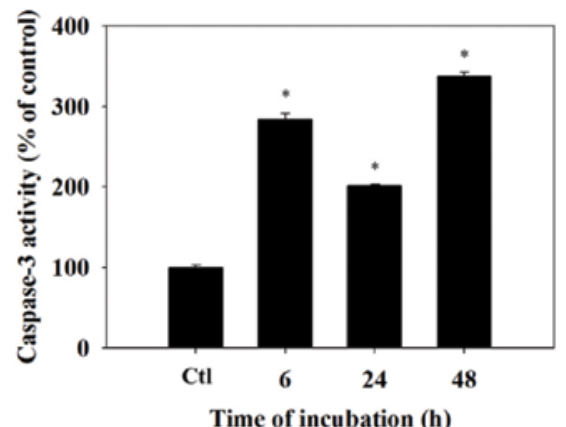
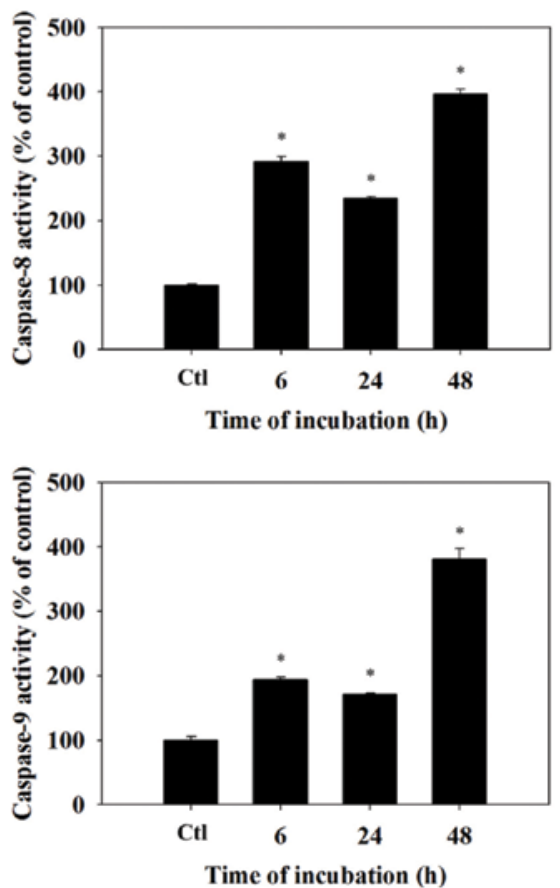

Figure 4. DMC stimulates the activities of caspase-3, -8 and -9 in the NCI-H460 cells. The cells were treated with $35 \mu \mathrm{M}$ DMC for $0,6,24$ and $48 \mathrm{~h}$ and then the activities of caspase-3 (A), -8 (B) and -9 (C) were determined by flow cytometric assay as described in Materials and methods. Significant differences from the control at ${ }^{*} \mathrm{P}<0.001$ by the Student's t-test. DMC, demethoxycurcumin.

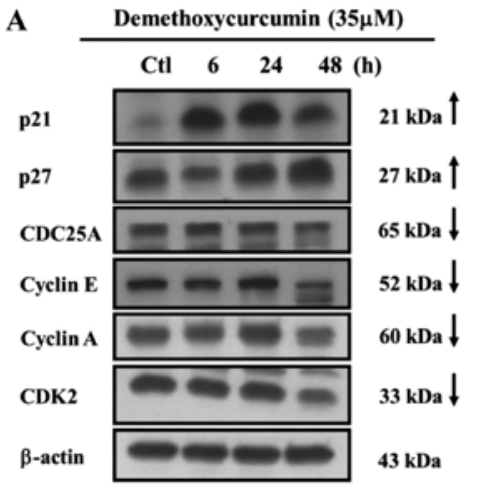

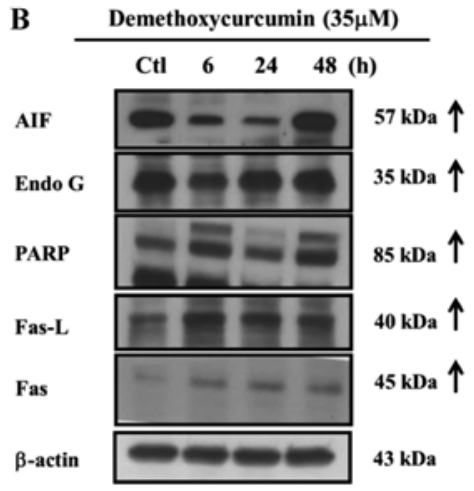

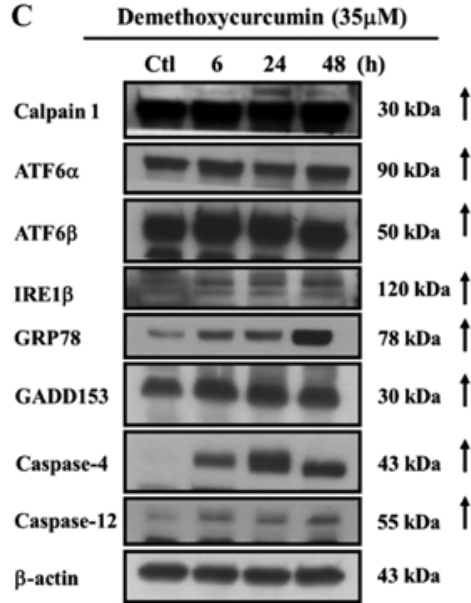

Figure 5. DMC affects the cell cycle and expression of apoptosis-associated proteins in the NCI-H460 cells. Cells were exposed to either vehicle or DMC $(35 \mu \mathrm{M})$ for various time periods. Cells were harvested and total proteins were determined and then protein expression was determined by western blotting as described in Materials and methods. (A) p21, p27, CDC25A, cyclin A, cyclin E and CDK2. (B) AIF, Endo G, PARP, Fas-L and Fas. (C) Calpain 1, ATF6a, ATF6 $\beta$, IRE1 $\beta$, GRP78, GADD153, caspase-12 and -4. DMC, demethoxycurcumin; Fas L, Fas ligand.

DMC affects cell cycle arrest and levels of apoptosis-associated proteins and protein translocation in the NCI-H46O cells. In order to investigate whether DMC induces apoptosis in NCI-H460 cells via changes in the cell cycle and levels of 
A

Ctl

FITC-AIF

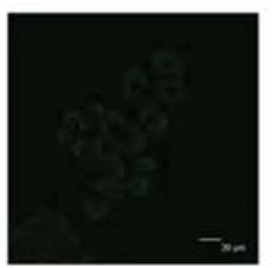

Demethoxycurcumin

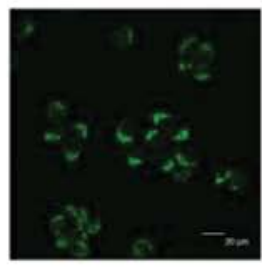

B

Ctl

FITC-Endo G

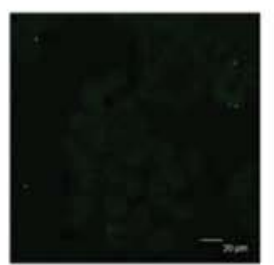

Demethoxycurcumin

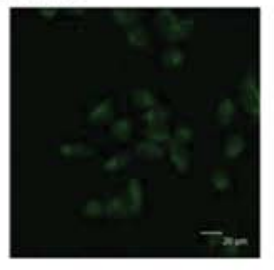

C

Ctl
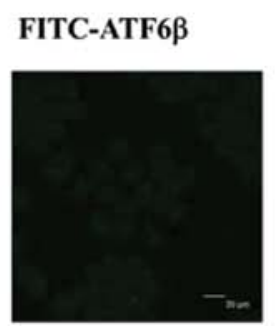

Demethoxycurcumin

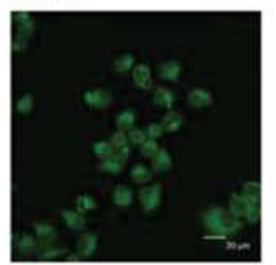

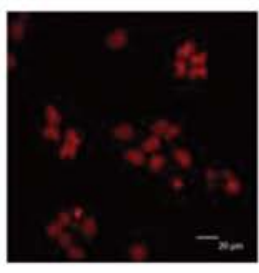

PI
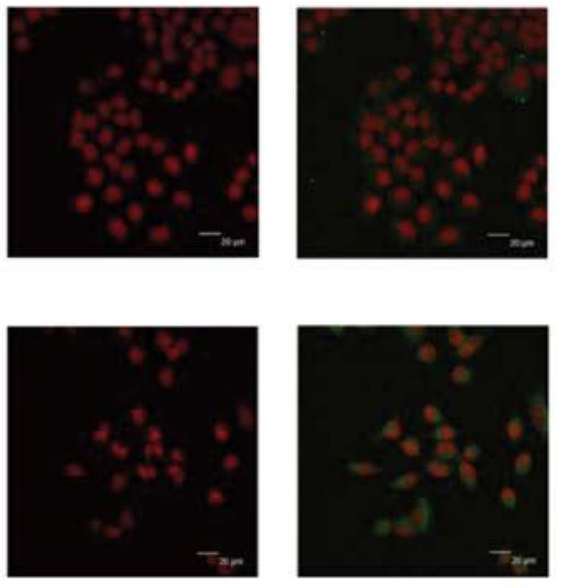

PI
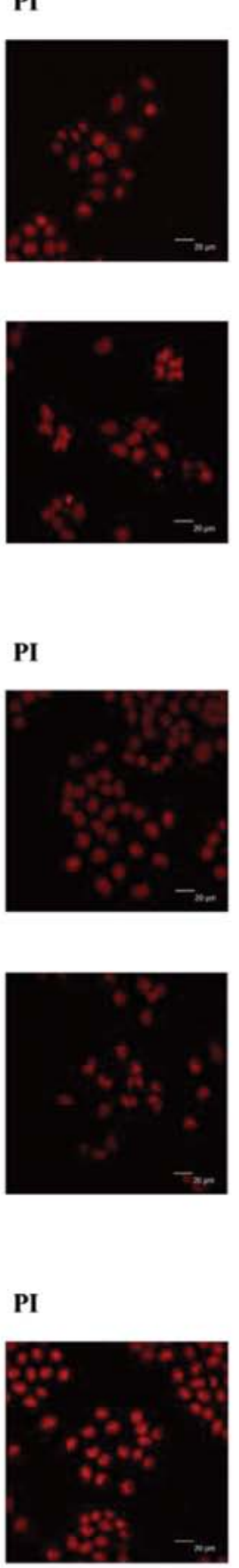

Merge
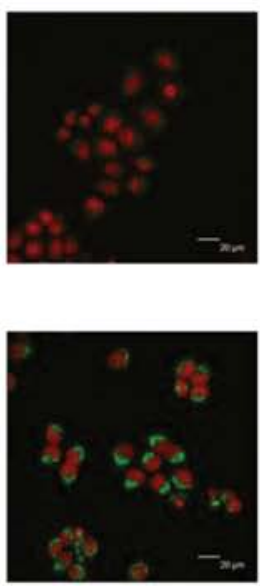

Merge

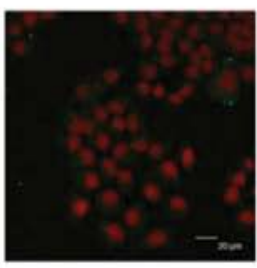

Merge
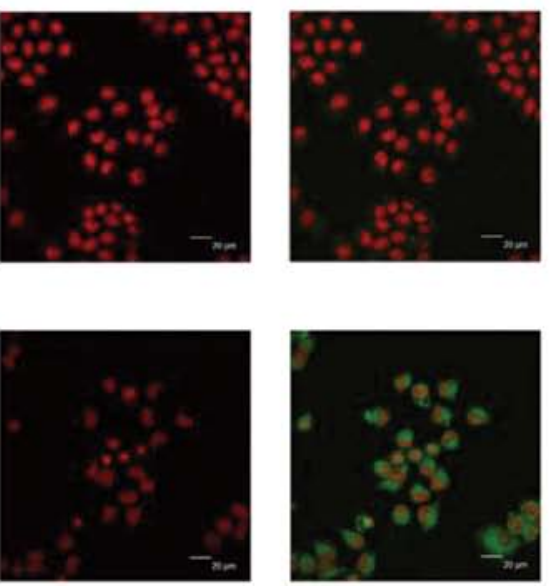

Figure 6. DMC affects the translocation of apoptosis-associated proteins in the NCI-H460 cells. Cells were treated with $35 \mu \mathrm{M}$ of DMC for $48 \mathrm{~h}$, stained with anti-AIF (A), -Endo G (B) and -ATF6 $\beta$ (C) and then stained with the secondary antibody (FITC-conjugated goat anti-mouse IgG (green fluorescence). Cells were examined and photographed using a Leica TCS SP2 confocal laser microscopic system as described in Materials and methods. DMC, demethoxycurcumin.

apoptosis-associated proteins, the NCI-H460 cells were treated with $35 \mu \mathrm{M}$ of DMC for $0,6,24$ and $48 \mathrm{~h}$ and then levels of total proteins from the samples were quantitated and the levels of apoptosis-associated proteins were measured by western blotting. DMC significantly promoted the expression of $\mathrm{p} 21$ and $\mathrm{p} 27$ but reduced the expression of CDC25A, cyclin E, 
D

Ctl

FITC-IRE1 $\alpha$

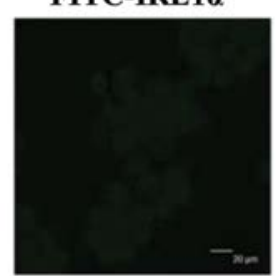

Demethoxycurcumin

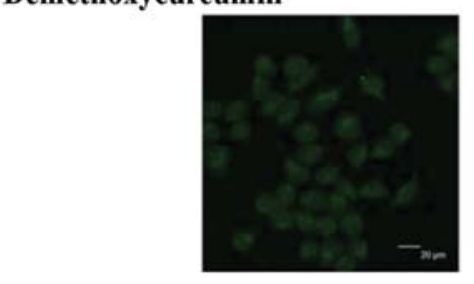

E

Ctl
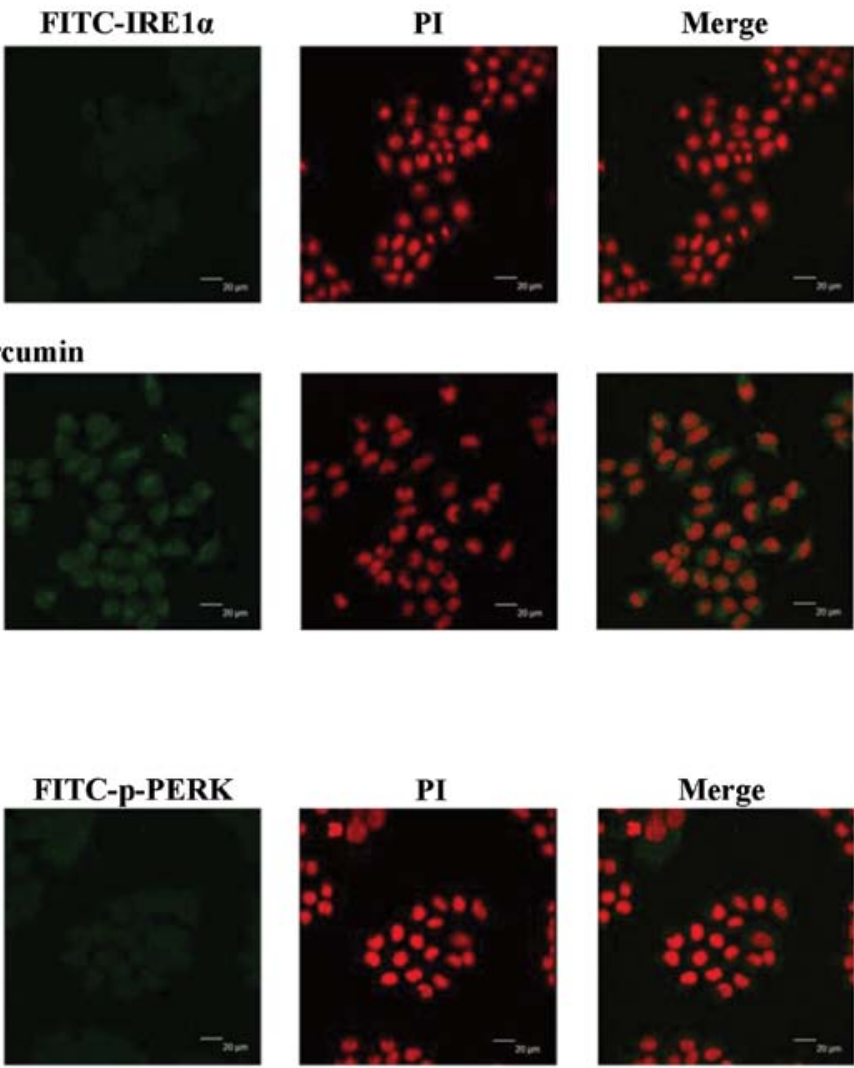

E

C
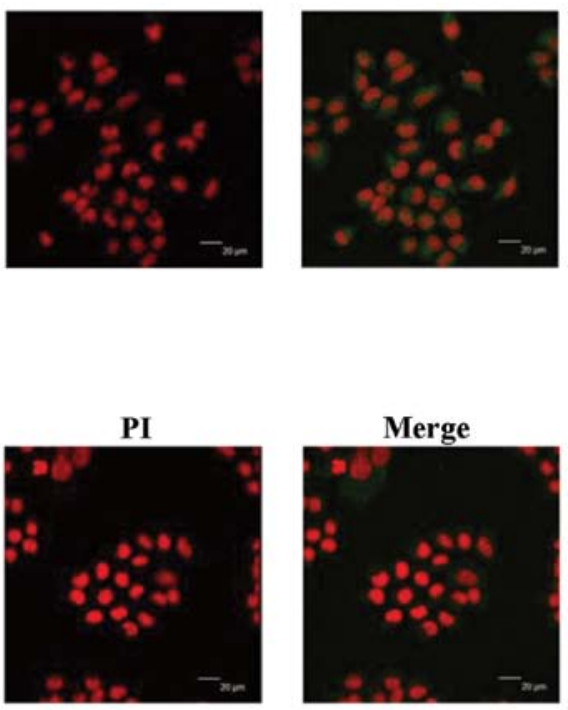

\section{Demethoxycurcumin}
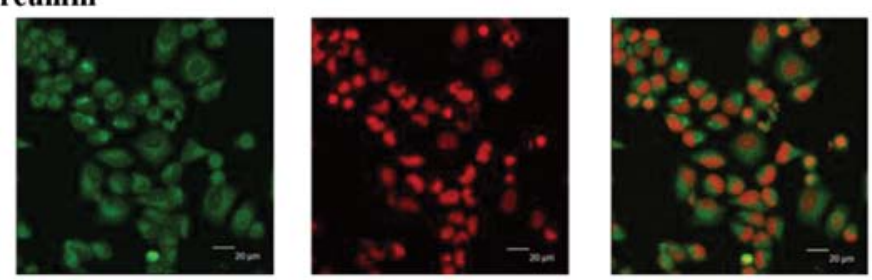

Figure 6. Continued. DMC affects the translocation of apoptosis-associated proteins in the NCI-H460 cells. Cells were treated with $35 \mu \mathrm{M}$ of DMC for $48 \mathrm{~h}$, stained with IRE1 $\alpha$ (D) and p-PERK (E) and then stained with the secondary antibody (FITC-conjugated goat anti-mouse IgG (green fluorescence). Cells were examined and photographed using a Leica TCS SP2 confocal laser microscopic system as described in Materials and methods. DMC, demethoxycurcumin.

cyclin A and CDK2 (Fig. 5A). AIF, Endo G, PARP, Fas ligand (Fas L) and Fas were also upregulated (Fig. 5B). Furthermore, DMC promoted expression of ER stress-associated proteins GRP78, GADD153, IRE1 $\beta$, ATF6 $\alpha$, ATF6 $\beta$, caspase-12 and -4 (Fig. 5C). Moreover, DMC promoted the expression of calpain 1 (Fig. 5C), which is associated with apoptotic pathways. The results revealed that DMC induced apoptosis in the NCI-H460 cells through caspase-, ER stress- and mitochondrial-dependent pathways. The results from the confocal laser microscopy also revealed that DMC promoted the release of AIF (Fig. 6A), Endo G (Fig. 6B), ATF6 $\beta$ (Fig. 6C), IRE1 $\alpha$ (Fig. 6D) and p-PERK (Fig. 6E) from the mitochondria to the cytosol and nuclei, respectively.

\section{Discussion}

Much evidence has shown that stimulating or inducing tumor cell apoptosis is one possibility for tumor treatment in patients with cancer. Although a few studies have shown that DMC induces cell death and apoptosis in human cancer cells as described previously, there is no study to show that DMC affects human lung cancer cells. The results of the present study revealed that DMC induced cell morphological changes (Fig. 1A and B) and decreased the percentage of viable cells (Fig. 1C) via the induction of the sub-G1 phase (apoptosis) and cell cycle arrest (Fig. 2A). DMC-induced apoptosis in the NCI-H460 cells was dose-dependent (Fig. 2B).

Dysregulation of the cell cycle is associated with tumorigenesis (18). We found that NCI-H460 cells were arrested at the $\mathrm{S}$ phase after treatment with DMC (Fig. 2A). Downregulation of CDK2, CDC25A, cyclin A and cyclin E as shown by western blotting (Fig. 5A), may be involved in the mechanism of this arrest. Based on the findings, DMC may exert its anticancer effects on NCI-H460 cells through both cell cycle arrest and apoptotic induction.

To further examine the molecular mechanism of DMC in NCI-H460 cells, we used flow cytometry and found that DMC significantly decreased the levels of $\Delta \Psi \mathrm{m}$ (Fig. 3B) 


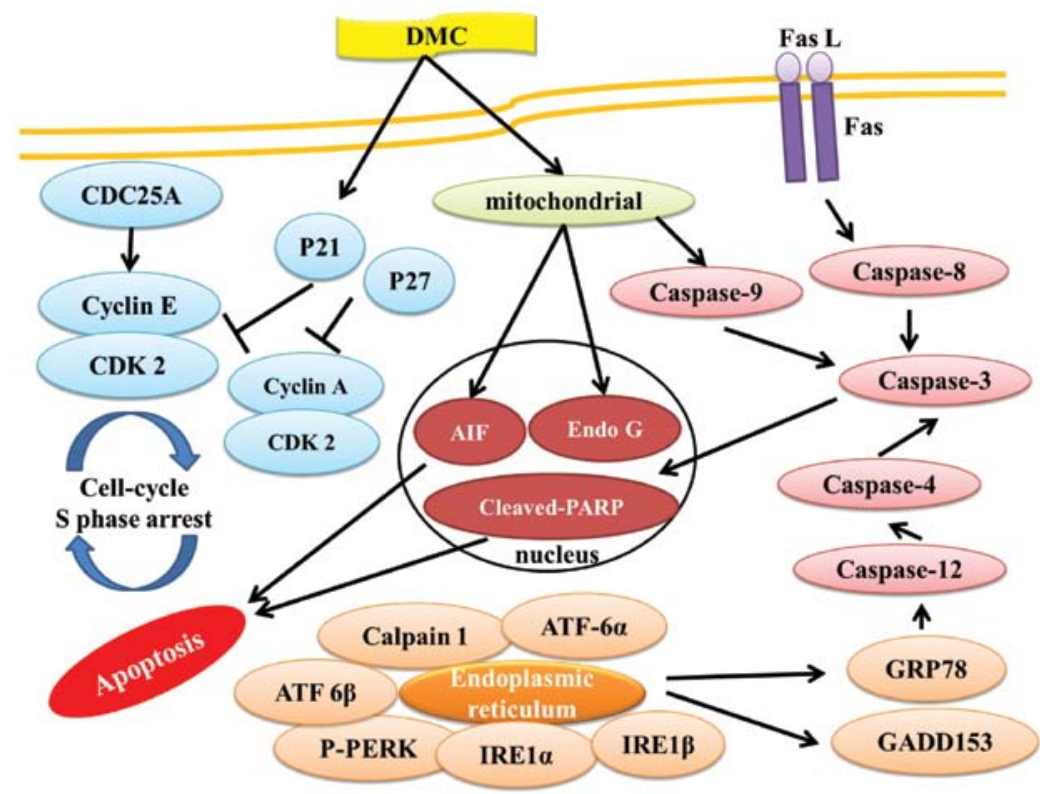

Figure 7. The possible signaling pathways involved in DMC-induced S phase arrest and apoptosis in NCI-H460 human lung cancer cells. DMC, demethoxycurcumin.

following a 24-h treatment and increased ROS and $\mathrm{Ca}^{2+}$ levels (Fig. 3A and C) at all treatment time periods. DMC also promoted the activities of caspase-3, -9 and -8 (Fig. 4).

Numerous studies have demonstrated that apoptotic cell death can occur through the extrinsic or the intrinsic apoptotic pathway (20-22). The agents (Fas L) connected with Fas (CD95) then trigger the extrinsic pathway followed by the activation of caspase- 8 and then activation of effector caspase-3 to cause cell apoptosis (23). Thus, we hypothesized that the extrinsic apoptotic pathway in NCI-H460 cells was activated following exposure to DMC. Thus, we used western blotting to examine the expression of FAS/CD95 in the NCI-H460 cells. The results revealed that DMC increased the expression of FAS/CD95 and Fas L (Fig. 5B) accompanied by increased caspase- 8 activity (Fig. 4B).

It is currently known that cancer cell survival or death following exposure to anticancer drugs is associated with mitochondrial function. Thus, anticancer drugs may induce cancer cell apoptosis through mitochondrial-dependent and -independent pathways. Anticancer drugs may induce mitochondrial dysfunction in cells via dissipation of $\Delta \Psi \mathrm{m}$ leading to liberation of numerous cell death proteins from the mitochondria (24). Therefore, it was reported that the intrinsic pathway depends on the dysfunction of the mitochondria resulting from an increase in the ratio of Bak:Bcl-2 which is caused by anticancer drugs thus leading to AIF and Endo $G$ release from the mitochondria before inducing apoptosis (25-27) which is termed caspase-independent pathways or alternatively causing cytochrome $c$ release, activation of caspase- 9 and -3 resulting in apoptosis termed the caspase-dependent pathway (28). Our results showed that DMC induced mitochondrial dysfunction (decreased levels of $\Delta \Psi \mathrm{m})$ (Fig. 3B) and increased caspase-8, -9 and -3 activity (Fig. 4) and increased the protein levels of AIF and Endo G (Fig. 5B) in the NCI-H460 cells. We also used confocal laser microscopy to confirm that DMC increased the expression of AIF and Endo G (Fig. 6A and B). Based on the findings, we suggest that DMC induced apoptosis in NCI-H460 cells through the mitochondrial-dependent and -independent pathways.

DMC induced ROS production in the NCI-H460 cells (Fig. 3A) and ROS have been shown to be involved in cell growth and apoptosis. An appropriate level of intracellular ROS promotes cellular proliferation (29), while excessive production of ROS may cause oxidative stress leading to cell apoptosis $(29,30)$.

It has been reported that ROS may induce ER stress which leads to the release of stored $\mathrm{Ca}^{2+}$ from the ER leading to mitochondrial $\mathrm{Ca}^{2+}$ loading from ER stores (31). Both ROS and ER $\mathrm{Ca}^{2+}$ are required to initiate mitochondrial dysfunction (31). Our results revealed that DMC increased the ROS and $\mathrm{Ca}^{2+}$ production (Fig. 3A and C). Furthermore, it was reported that mitochondria take up $\mathrm{Ca}^{2+}$ and initiate apoptosis through opening of their permeability transition pores (32). This then results in the release of cytochrome $c$ from the mitochondrial membrane which then activates caspase- 9 and triggers the effector caspase-3 for causing apoptosis (33). It was reported that markers of ER stress such as transcriptionally induced GRP78 and GADD153 are produced (31). We found that DMC increased the protein levels of GRP78, GADD153, IRE1 $\beta$, ATF6 $\alpha$, ATF6 $\beta$, caspase-12 and -4 and the expression of calpain 1 (Fig. 5C), that are associated with apoptosis pathways.

In conclusion, DMC induced cell death (cytotoxic effect) in human lung cancer NCI-H460 cells, mediated through the induction of phase $\mathrm{S}$ cell cycle arrest by inhibition of the check-point proteins CDC25A, cyclin A, cyclin E and CDK2 and induced cell apoptosis associated with caspaseor mitochondrial-dependent pathways. Furthermore, DMC induced cell apoptosis also through cross-talk between the extrinsic and the intrinsic pathway as summarized in Fig. 7. DMC appears to have multiple molecular targets, and its 
application in the treatment of lung cancer patients warrants further investigation.

\section{Acknowledgements}

This study was supported in part by a research grant from China Medical University (no. CMU102-ASIA-20). Experiments and data analysis were performed in part through the use of the Medical Research Core Facilities Center, Office of Research and Development at China Medical University, Taichung, Taiwan, R.O.C.

\section{References}

1. Siegel R, Naishadham D and Jemal A: Cancer statistics, 2013. CA Cancer J Clin 63: 11-30, 2013.

2. Non-small Cell Lung Cancer Collaborative Group: Chemotherapy in non-small cell lung cancer: a meta-analysis using updated data on individual patients from 52 randomised clinical trials. BMJ 311: 899-909, 1995.

3. Sandler A, Gray R, Perry MC, Brahmer J, Schiller JH, Dowlati A, Lilenbaum $\mathrm{R}$ and Johnson DH: Paclitaxel-carboplatin alone or with bevacizumab for non-small-cell lung cancer. N Engl J Med 355: 2542-2550, 2006

4. Jayaprakasha GK, Jagan Mohan Rao L and Sakariah KK: Improved HPLC method for the determination of curcumin demethoxycurcumin, and bisdemethoxycurcumin. J Agric Food Chem 50: 3668-3672, 2002.

5. Balasubramanyam M, Koteswari AA, Kumar RS, Monickaraj SF, Maheswari JU and Mohan V: Curcumin-induced inhibition of cellular reactive oxygen species generation: novel therapeutic implications. J Biosci 28: 715-721, 2003.

6. Chan WH, Wu HJ and Hsuuw YD: Curcumin inhibits ROS formation and apoptosis in methylglyoxal-treated human hepatoma G2 cells. Ann NY Acad Sci 1042: 372-378, 2005

7. PriyadarsiniKI,Maity DK,Naik GH,KumarMS,UnnikrishnanMK, Satav JG and Mohan H: Role of phenolic O-H and methylene hydrogen on the free radical reactions and antioxidant activity of curcumin. Free Radic Biol Med 35: 475-484, 2003.

8. AhmedT andGilani AH:Inhibitory effect of curcuminoidson acetylcholinesterase activity and attenuation of scopolamine-induced amnesia may explain medicinal use of turmeric in Alzheimer's disease. Pharmacol Biochem Behav 91: 554-559, 2009.

9. Luthra PM, Kumar R and Prakash A: Demethoxycurcumin induces Bcl-2 mediated G2/M arrest and apoptosis in human glioma U87 cells. Biochem Biophys Res Commun 384: 420-425, 2009.

10. Yodkeeree S, Chaiwangyen W, Garbisa S and Limtrakul P: Curcumin, demethoxycurcumin and bisdemethoxycurcumin differentially inhibit cancer cell invasion through the down-regulation of MMPs and uPA. J Nutr Biochem 20: 87-95, 2009.

11. Tamvakopoulos C, Dimas K, Sofianos ZD, Hatziantoniou S, Han Z, Liu ZL, Wyche JH and Pantazis P: Metabolism and anticancer activity of the curcumin analogue, dimethoxycurcumin. Clin Cancer Res 13: 1269-1277, 2007.

12. Lee JW, Hong HM, Kwon DD, Pae HO and Jeong HJ: Dimethoxycurcumin, a structural analogue of curcumin, induces apoptosis in human renal carcinoma caki cells through the production of reactive oxygen species, the release of cytochrome $c$ and the activation of caspase-3. Korean J Urol 51: 870-878, 2010.

13. Anuchapreeda S, Tima S, Duangrat $C$ and Limtrakul P: Effect of pure curcumin, demethoxycurcumin, and bisdemethoxycurcumin on WT1 gene expression in leukemic cell lines. Cancer Chemother Pharmacol 62: 585-594, 2008.
14. Ji BC, Hsu WH, Yang JS, et al: Gallic acid induces apoptosis via caspase- 3 and mitochondrion-dependent pathways in vitro and suppresses lung xenograft tumor growth in vivo. J Agric Food Chem 57: 7596-7604, 2009.

15. Lin SY, Lai WW, Ho CC, et al: Emodin induces apoptosis of human tongue squamous cancer SCC-4 cells through reactive oxygen species and mitochondria-dependent pathways. Anticancer Res 29: 327-335, 2009.

16. Gorczyca W, Melamed MR and Darzynkiewicz Z: Laser scanning cytometer (LSC) analysis of fraction of labelled mitoses (FLM). Cell Prolif 29: 539-547, 1996.

17. Hsia TC, Yang JS, Chen GW, et al: The roles of endoplasmic reticulum stress and $\mathrm{Ca}^{2+}$ on rhein-induced apoptosis in A-549 human lung cancer cells. Anticancer Res 29: 309-318, 2009.

18. Diehl JA: Cycling to cancer with cyclin D1. Cancer Biol Ther 1: 226-231, 2002.

19. Liu DD, Ye YL, Zhang J, Xu JN, Qian XD and Zhang Q: Distinct pro-apoptotic properties of Zhejiang saffron against human lung cancer via a caspase-8-9-3 cascade. Asian Pac J Cancer Prev 15: 6075-6080, 2014.

20. Kumar S: Caspase function in programmed cell death. Cell Death Differ 14: 32-43, 2007.

21. Wilson MR: Apoptotic signal transduction: Emerging pathways. Biochem Cell Biol 76: 573-582, 1998.

22. Xu G and Shi Y: Apoptosis signaling pathways and lymphocyte homeostasis. Cell Res 17: 759-771, 2007.

23. Kim HJ, Yang KM, Park YS, Choi YJ, Yun JH, Son CH, Suh HS, Jeong MH and Jo WS: The novel resveratrol analogue HS-1793 induces apoptosis via the mitochondrial pathway in murine breast cancer cells. Int J Oncol 41: 1628-1634, 2012.

24. Tait SW and Green DR: Mitochondria and cell death: Outer membrane permeabilization and beyond. Nat Rev Mol Cell Biol 11: 621-632, 2010.

25. Baek SH, Bae ON, Kim EK and Yu SW: Induction of mitochondrial dysfunction by poly(ADP-ribose) polymer: implication for neuronal cell death. Mol Cells 36: 258-266, 2013.

26. Liou GY and Storz P: Reactive oxygen species in cancer. Free Radic Res 44: 479-496, 2010.

27. Liu KC, Huang YT, Wu PP, Ji BC, Yang JS, Yang JL, Chiu TH, Chueh FS and Chung JG: The roles of AIF and Endo G in the apoptotic effects of benzyl isothiocyanate on DU 145 human prostate cancer cells via the mitochondrial signaling pathway. Int J Oncol 38: 787-796, 2011.

28. Yoo JO, Lim YC, Kim YM and Ha KS: Transglutaminase 2 promotes both caspase-dependent and caspase-independent apoptotic cell death via the calpain/Bax protein signaling pathway. J Biol Chem 287: 14377-14388, 2012.

29. Circu ML and Aw TY: Reactive oxygen species, cellular redox systems, and apoptosis. Free Radic Biol Med 48: 749-762, 2010.

30. Hajnóczky G, Csordás G, Das S, Garcia-Perez C, Saotome M, Sinha Roy S and Yi M: Mitochondrial calcium signalling and cell death: approaches for assessing the role of mitochondrial $\mathrm{Ca}^{2+}$ uptake in apoptosis. Cell Calcium 40: 553-560, 2006.

31. Jacobson J and Duchen MR: Mitochondrial oxidative stress and cell death in astrocytes - requirement for stored $\mathrm{Ca}^{2+}$ and sustained opening of the permeability transition pore. J Cell Sci 115: $1175-1188,2002$.

32. Garrido C, Galluzzi L, Brunet M, Puig PE, Didelot C and Kroemer G: Mechanisms of cytochrome $c$ release from mitochondria. Cell Death Differ 13: 1423-1433, 2006.

33. Rao RV, Ellerby HM and Bredesen DE: Coupling endoplasmic reticulum stress to the cell death program. Cell Death Differ 11: 372-380, 2004. 